\title{
Modificações no pogônio e no nariz de acordo com o modo respiratório
}

\author{
Orlando Tanaka*, Suelem Tisiane Fabianski**, Lílian Mary Karakida**,

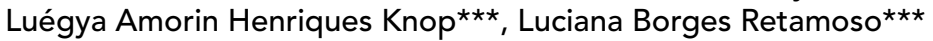

\begin{abstract}
Resumo
Introdução: o perfil mole do indivíduo é resultado de mudanças complexas que ocorrem nos tecidos duros e moles das estruturas faciais. $\mathrm{O}$ pogônio e o nariz são estruturas dominantes na face e influenciam no grau de convexidade do perfil. Assim, é fundamental a análise das estruturas do pogônio e a inclusão das estruturas nasais no plano de tratamento ortodôntico. Objetivo: avaliar longitudinalmente as modificações dimensionais no plano anteroposterior do pogônio e do nariz de indivíduos com má oclusão de Classe II, divisão 1 de Angle, em dois momentos distintos do desenvolvimento craniofacial. Métodos: foram realizados traçados cefalométricos sobre telerradiografias em norma lateral de 40 indivíduos, sendo 23 respiradores predominantemente nasais $(\mathrm{RN})$ e 17 predominantemente bucais $(\mathrm{RB})$. Resultados: foram obtidas as medidas lineares e angulares LS'-Pog', LS'-B', B'-Pog', Pog'-PogTeg', Linha NB, Pog-NB, N'-Prn, Prn-NPog, N-Prn-Sn e Prn-Sn-LS. O teste ANOVA a dois critérios com medidas repetidas foi aplicado para indicar diferenças entre os valores médios dessas variáveis segundo os momentos e/ou modo respiratório. Observou-se que as variáveis LS'-B', Pog'-PogTeg', Linha NB e Pog-NB, N'-Prn, Prn-NPog, N-Prn-Sn e Prn-Sn-LS apresentaram diferença significativa $(p \leq 0,05)$ quando comparados os momentos final e inicial, embora não houvesse diferença significativa entre os modos respiratórios. Em nenhuma das variáveis se observou interação entre o modo respiratório e os momentos. Conclusão: há alteração estatisticamente significativa do pogônio e do nariz no plano anteroposterior no decorrer do crescimento, porém sem qualquer interferência do modo respiratório.
\end{abstract}

Palavras-chave: Nariz. Pogônio. Respiração nasal. Respiração bucal.

\section{INTRODUÇÃO}

O perfil mole do indivíduo é resultado de mudanças que ocorrem nos tecidos esqueléticos e tegumentares das estruturas da face, e a inter-relação entre os componentes dos tecidos moles

Como citar este artigo: Tanaka O, Fabianski ST, Karakida LM, Knop LAH, Retamoso LB. Modificações no pogônio e no nariz de acordo com o modo respiratório. Dental Press J Orthod. 2011 Nov-Dec;16(6):78-83. da face - como o nariz, os lábios e o pogônio modifica-se durante o crescimento e no decorrer do tratamento ortodôntico. Sendo assim, é importante compreender as tendências normais do crescimento dessas estruturas $^{18}$. Ao nascimento,

* Professor Titular do Curso de Odontologia da PUCPR. Diplomado pelo Board Brasileiro de Ortodontia.

** Estudante da graduação em Odontologia na PUCPR.

*** Estudante do mestrado em Ortodontia na PUCPR. 
o pogônio é mais retruído em relação à maxila, e essa diferença tende a diminuir com o crescimento da mandíbula. Os indivíduos do sexo masculino tendem a apresentar medidas maiores que as do sexo feminino ${ }^{28}$, e a modificação no mento não é característica de nenhuma má oclusão.

O nariz, sendo o fator mais dominante de todos os elementos do perfil ${ }^{17}$, ainda recebe pouca atenção na análise ortodôntica, embora algumas análises faciais (Steiner ${ }^{29}$, Ricketts ${ }^{21}$, Holdaway ${ }^{12}$ e Chaconas $^{4}$ ) utilizem o nariz como um ponto de referência ou como mais um elemento de informação.

Quanto à influência do modo respiratório sobre a morfologia do complexo dentoesquelético, há muitas publicações na literatura, mas ainda muita discordância entre os autores. Alguns relatam que a obstrução da respiração nasal altera o crescimento e o desenvolvimento facial; outros afirmam que o crescimento alterado do complexo dentofacial é resultado de fatores do meio ambiente e fatores genéticos ${ }^{30}$.

O conhecimento do crescimento nasal e do pogônio e do seu relacionamento com a face é interessante para o cirurgião-dentista. É valiosa a capacidade de predizer a quantidade, direção e tamanho desse crescimento, sobretudo em indivíduos com respiração predominantemente bucal e predominantemente nasal.

\section{PROPOSIÇÃO}

Avaliar, longitudinalmente, as modificações dimensionais no plano anteroposterior do pogônio e do nariz de indivíduos com má oclusão de Classe II, divisão 1 de Angle, em dois momentos distintos do desenvolvimento craniofacial.

\section{MATERIAL E MÉTODOS}

A amostra foi composta por telerradiografias em norma lateral de 40 indivíduos com má oclusão de Classe II, divisão 1 de Angle, 23 respiradores predominantemente nasais (RN) e 17 respiradores predominantemente bucais (RB), com idades entre 10 anos e 9 meses e 14 anos (momento 1), e entre 13 anos e 4 meses e 16 anos e 6 meses (momento 2).

A classificação do modo respiratório foi realizada de acordo com o método proposto por Wieler et al. ${ }^{24}$, de maneira multidisciplinar, incluindo avaliação clínica do selamento labial realizada por cirurgião-dentista; questionário respondido pelos pais quanto aos hábitos de respiração; avaliação otorrinolaringológica realizada por especialista; e avaliação fonoaudiológica realizada por especialista. Em seguida, foram atribuídos pontos e pesos ponderados para cada avaliação, gerando um índice para classificar o modo respiratório predominante nos indivíduos.

A avaliação cefalométrica foi realizada por meio da combinação dos métodos manual e computadorizado ${ }^{25}$. O desenho das estruturas anatômicas foi realizado manualmente e, após a digitalização do traçado, foram demarcados os pontos e os valores cefalométricos mensurados utilizando-se o programa de cefalometria Radiocef $2000^{\circledR}$. Os modelos de estudo foram utilizados para auxiliar no traçado das relações dentárias.

As medidas utilizadas são descritas a seguir.

\section{Medidas lineares referentes ao pogônio}

»LS'-Pog': medida do ponto LS' ao ponto Pog', correspondente à maior dimensão ou distância anteroposterior da imagem lateral da sínfise mandibular (espessura total da sínfise).

» LS'-B': medida do ponto LS' ao ponto B', correspondente à maior dimensão ou distância anteroposterior da imagem lateral da sínfise mandibular.

» B'-Pog': medida do ponto B' ao ponto Pog', correspondente à maior dimensão ou distância anteroposterior da imagem lateral da sínfise mandibular.

»Pog'-PogTeg': medida do ponto Pog' ao ponto PogTeg', correspondente à maior dimensão ou distância anteroposterior da imagem lateral da sínfise mandibular.

»Linha NB: união dos pontos $\mathrm{N}$ e B. 
»Pog-NB: distância do ponto Pog à linha NB. Indica a proeminência óssea na região mais anterior do mento, a partir da linha NB. Valores positivos, quando localizados à frente da linha; e negativos, quando situados aquém da linha NB.

\section{Medidas lineares referentes ao nariz}

" N'-Prn: medida da posição da ponta do nariz em relação ao násio. Determina a projeção do nariz.

»Prn-NPog: medida da profundidade nasal em relação ao plano facial.

\section{Medidas angulares referentes ao nariz}

» N-Prn-Sn: medida da proeminência do nariz em relação à linha sela-násio.

»Prn-Sn-LS: ângulo nasolabial - medida da inclinação da columela em relação ao lábio superior.

\section{RESULTADOS}

Pogônio

Uma vez que todas as variáveis, em todos os momentos, apresentaram distribuição normal, por meio do teste estatístico Kolmogorov-Smirnov, com exceção de B'-Pog' e Pog-NB, a comparação dos valores médios segundo os momentos foi feita pelo ANOVA a dois critérios com medidas repetidas.

Os resultados da aplicação do ANOVA mostraram que o valor da estatística $F$ foi significativo $(\mathrm{p}<0,05)$ para as medidas LS'-B', Pog'-PogTeg', linha NB, Pog-NB, indicando existir diferença entre os valores médios das variáveis segundo os momentos e/ou o modo respiratório. As variáveis B'-Pog' e LS'-PogTeg' não apresentaram diferença estatisticamente significativa $(\mathrm{p}>0,05)$ entre os tratamentos (modo respiratório x momentos). Para identificar quais tratamentos (modo respiratório $\mathrm{x}$ momentos) diferiam entre si, foi utilizado o teste de comparações múltiplas de Tukey HSD (Tab. 1).

TABELA 1 - Comparações múltiplas de Tukey HSD modo respiratório.

\begin{tabular}{|c|c|c|c|c|c|}
\hline Modo Respiratório & Momento & Nasal Inicial & Nasal Final & Bucal Inicial & Bucal Final \\
\hline LS'-B' & Médias & 10,08 & 8,96 & 9,75 & 8,95 \\
\hline Nasal & Inicial & - & $0,000225^{*}$ & 0,973068 & 0,215061 \\
\hline Nasal & Final & $0,000225^{*}$ & - & 0,516552 & 1,000000 \\
\hline Bucal & Inicial & 0,973068 & 0,516552 & - & $0,020579 *$ \\
\hline Bucal & Final & 0,215061 & 1,000000 & $0,020579^{*}$ & - \\
\hline Pog'- PogTeg' & Médias & 10,54 & 10,80 & 10,40 & 10,98 \\
\hline Nasal & Inicial & - & 0,327002 & 0,888784 & 0,557792 \\
\hline Nasal & Final & 0,327002 & - & 0,585907 & 0,864706 \\
\hline Bucal & Inicial & 0,888784 & 0,585907 & - & 0,049538 \\
\hline Bucal & Final & 0,557792 & 0,864706 & 0,049538 & - \\
\hline Linha NB & Médias & 95,95 & 100,03 & 98,73 & 101,48 \\
\hline Nasal & Inicial & - & $0,000166^{*}$ & 0,638323 & $0,012703^{*}$ \\
\hline Nasal & Final & $0,000166^{*}$ & - & 0,873554 & 0,924643 \\
\hline Bucal & Inicial & 0,638323 & 0,873554 & - & $0,0029667^{*}$ \\
\hline Bucal & Final & $0,012703^{*}$ & 0,924643 & $0,0029667^{*}$ & - \\
\hline Pog-NB & Médias & 1,85 & 2,43 & 1,27 & 1,87 \\
\hline Nasal & Inicial & - & $0,005911^{*}$ & 0,841574 & 0,997777 \\
\hline Nasal & Final & $0,005911^{*}$ & - & 0,108289 & 0,880566 \\
\hline Bucal & Inicial & 0,841574 & 0,108289 & - & $0,009903^{*}$ \\
\hline Bucal & Final & 0,997777 & 0,880566 & $0,009903^{*}$ & - \\
\hline
\end{tabular}

*Diferença estatisticamente significativa $(p \leq 0,05)$. 
TABELA 2 - Comparações múltiplas de Tukey HSD modo respiratório.

\begin{tabular}{|c|c|c|c|c|c|}
\hline Modo Respiratório & Momento & Nasal Inicial & Nasal Final & Bucal Inicial & Bucal Final \\
\hline$N^{\prime}-\operatorname{Prn}$ & Médias & 48,46 & 51,17 & 48,65 & 51,09 \\
\hline Nasal & Inicial & - & $0,000168^{*}$ & 0,998581 & $0,032712^{*}$ \\
\hline Nasal & Final & $0,000168^{*}$ & - & $0,043527^{*}$ & 0,999881 \\
\hline Bucal & Inicial & 0,998581 & $0,043527^{*}$ & - & $0,000426^{*}$ \\
\hline Bucal & Final & $0,032712^{*}$ & 0,999881 & $0,000426^{*}$ & - \\
\hline Prn-NPog & Médias & 31,44 & 33,37 & 31,16 & 33,54 \\
\hline Nasal & Inicial & - & 0,057858 & 0,996643 & 0,239205 \\
\hline Nasal & Final & 0,057858 & - & 0,200245 & 0,999237 \\
\hline Bucal & Inicial & 0,996643 & 0,200245 & - & $0,038587^{*}$ \\
\hline Bucal & Final & 0,239205 & 0,999237 & $0,038587^{*}$ & - \\
\hline N-Prn-Sn & Médias & 99,74 & 96,09 & 100,88 & 98,00 \\
\hline Nasal & Inicial & - & $0,000591^{*}$ & 0,961845 & 0,763410 \\
\hline Nasal & Final & $0,000591^{*}$ & - & $0,046302^{*}$ & 0,847989 \\
\hline Bucal & Inicial & 0,961845 & $0,046302^{*}$ & - & $0,024001^{*}$ \\
\hline Bucal & Final & 0,763410 & 0,847989 & $0,024001^{*}$ & - \\
\hline Prn-Sn-LS & Médias & 0,763410 & 126,48 & 120,59 & 122,76 \\
\hline Nasal & Inicial & 0,763410 & $0,043676^{*}$ & 0,430122 & 0,719993 \\
\hline Nasal & Final & 0,763410 & - & 0,060697 & 0,372458 \\
\hline Bucal & Inicial & 0,763410 & 0,060697 & - & 0,142717 \\
\hline Bucal & Final & 0,763410 & 0,372458 & 0,142717 & - \\
\hline
\end{tabular}

*Diferença estatisticamente significativa $(p \leq 0,05)$.

\section{Nariz}

A verificação da hipótese estabelecida foi feita pela análise de variância a dois critérios de classificação, com medidas repetidas (ANOVA), quando os dois momentos e os dois modos respiratórios (tratamentos) apresentaram distribuição normal para a variável em análise. A verificação da normalidade foi realizada por meio do teste de normalidade de Kolmogorov-Smirnov, ao nível de significância de 0,05.

Quando a ANOVA indicou existir diferença entre os valores médios das variáveis N'-Prn, Prn-NPog, N-Prn-Sn, Prn-Sn-LS segundo os momentos e/ou modo respiratório, utilizou-se para identificar quais tratamentos (modo respiratório x momentos) diferiam entre si o teste de comparações múltiplas de Tukey HSD (Tab. 2).

\section{DISCUSSÃO}

A análise facial é um recurso empregado e valori- zado na elaboração do diagnóstico desde os primórdios da Ortodontia ${ }^{20}$, sendo que os lábios, bochechas e, em especial, o nariz são capazes de caracterizar a aparência facial única de cada indivíduo ${ }^{19}$.

O crescimento esquelético e as alterações nos tecidos moles influenciam a oclusão e estética facial. A quantidade de tecido mole sobre a sínfise tem papel fundamental na harmonia facial e na resposta das alterações esqueléticas ${ }^{5}$. Ainda, os valores numéricos obtidos com a cefalometria fornecem informações concretas, embora bidimensionais, que possibilitam avaliações comparativas e complementam o diagnóstico $^{16}$. Assim, a cefalometria é amplamente utilizada em diversas metodologias científicas ${ }^{10,11}$.

As alterações nos tecidos moles e duros da face devem ser consideradas durante o diagnóstico e plano de tratamento ortodôntico ${ }^{2,22,28}$, sendo observadas diferenças entre os sexos e em diferentes idades quanto ao crescimento dessas estruturas ${ }^{11}$. 
Os resultados do presente estudo demonstraram que houve alteração nas medidas do pogônio esquelético e tegumentar nos dois momentos avaliados (10-14 e 13-16 anos de idade), o que está de acordo com outros autores ${ }^{13,15}$. A diferença de espessura do pogônio (medida LS'-Pog') ocorreu por causa da remodelação óssea diferenciada, com maior aposição óssea na região lingual do pogônio, característica da fase do crescimento, conforme comprovado por estudos histológicos ${ }^{6}$ e com implantes metálicos ${ }^{1}$.

No presente estudo, observou-se que o pogônio tegumentar esteve diretamente relacionado ao incremento no pogônio esquelético, contrariamente ao que relataram Genecov, Sinclair e Dechow $^{9}$, que o crescimento do pogônio tegumentar em pacientes que realizaram tratamento ortodôntico é constante e relativamente independente do tecido ósseo subjacente.

Em relação à medida B'-Pog', verificou-se diminuição nos indivíduos respiradores predominantemente nasais e aumento nos respiradores predominantemente bucais. O presente estudo, no entanto, não avaliou a razão da diminuição dessa medida nos indivíduos respiradores predominantemente nasais. Supõe-se que ocorreu um deslocamento para posterior menor do ponto $\mathrm{B}$, consequência da rotação da mandíbula para baixo e para trás, não desconsiderando a possibilidade de menor crescimento aposicional na região do pogônio.

A diminuição da medida LS'-B' e o aumento de Pog-NB podem ser interpretados pelo deslocamento posterior do ponto B e pela aposição óssea na região do pogônio. Além disso, há variações na inclinação do ângulo do plano mandibular. Para Rosenstein $^{23}$, a variável LS'-B' tende a ser menor ainda nos indivíduos tratados com extrações dentárias.

Segundo Prahl-Andersen et al. ${ }^{18}$, o comprimento, a proeminência e morfologia nasal estão associados com o crescimento em altura e comprimento da maxila e da mandíbula.

A projeção nasal no plano posteroanterior apresentou alteração estatisticamente significati- va no presente estudo, o que está de acordo com Brant et al. ${ }^{3}$, que demonstraram modificações significativas em N-Prn-Sn quando compararam os grupos com extração e sem extração de pré-molares. Segundo Chaconas ${ }^{4}$, a ponta do nariz cresce numa direção mais para baixo nos indivíduos com má oclusão de Classe II.

O ângulo nasolabial (Prn-Sn-LS) revelou alterações significativas $(\mathrm{p} \leq 0,05)$ entre os dois momentos, em decorrência do crescimento nasal e da retração do lábio superior que ocorrem durante o desenvolvimento normal do indivíduo, podendo ocorrer também alongamento do sulco nasolabial ${ }^{7}$. Os resultados obtidos concordam com os de Salgado et al. ${ }^{26}$, que observaram variações significativas no ângulo nasolabial em indivíduos com más oclusões de Classes II e III, sendo os valores maiores nas Classes II. No entanto, os resultados discordam dos de Brant et al. ${ }^{3}$, que não observaram diferenças significativas no ângulo nasolabial de indivíduos tratados ortodonticamente com ou sem exodontias.

A respiração nasal é primordial para que haja um correto crescimento e desenvolvimento do complexo craniofacia ${ }^{27}$. Em alguns estudos, foram observadas diferenças no desenvolvimento craniofacial entre respiradores bucais e nasais, de forma que os respiradores predominantemente bucais apresentam maior inclinação do ângulo do plano mandibular e padrão de crescimento vertical ${ }^{14,28}$. Essa afirmação discorda dos resultados do presente estudo, pois não foi verificada interação com o modo respiratório em nenhuma das variáveis estudadas.

Portanto, as modificações na espessura dos tecidos tegumentares do nariz, lábios e pogônio devem ser consideradas no diagnóstico, na elaboração do plano de tratamento e na execução do tratamento em indivíduos em fase de crescimento.

\section{CONCLUSÃO}

Conclui-se que houve modificação no pogônio esquelético e tegumentar e no nariz no plano anteroposterior, no decorrer do crescimento, porém sem interferência do modo respiratório. 


\title{
Changes in pogonion and nose according to breathing patterns
}

\begin{abstract}
Introduction: The soft profile results from complex changes in the head and facial soft tissues. The pogonion and the nose are dominant facial structures that determine the degree of profile convexity and should, therefore, be analyzed and included in orthodontic treatment planning. Objective: To conduct a longitudinal evaluation of the anteroposterior dimensional changes of the pogonion and the nose of individuals with Angle Class II, division 1 malocclusion at two time points during craniofacial development. Methods: Cephalometric tracings of lateral radiographs were obtained for 40 individuals classified according to their predominant breathing pattern; 23 were nose breathers (NB), and 17, mouth breathers (MB). Results: Linear and angular measures were obtained: Ls-Pog, Ls-B, B-Pog, Pog-soft tissue Pog, NB Line, Pog-NB, N-Prn, Prn-NPog, N-Prn-Sn and Prn-SnLs. Two-way ANOVA was used to detect differences between mean values according to time points and breathing patterns. The Ls-B, Pog-soft tissue Pog, NB Line and Pog-NB, N-Prn, Prn-NPog, N-Prn-Sn and Prn-Sn-Ls variables had significant differences $(p \leq 0.05)$ between the two time points, but there were no significant differences between breathing patterns. No interaction was found between breathing patterns and time points for any variable. Conclusion: The pogonion and the nose undergo significant changes in the anteroposterior plane along growth, but breathing patterns do not affect changes significantly.
\end{abstract}

Keywords: Nose. Pogonion. Nose breathing. Mouth breathing.

\section{REFERÊNCIAS}

1. Bjork A. Variations in the growth pattern of the human mandible: longitudinal radiographic study by the implant method. J Dent Res. 1963;42(1)Pt 2:400-11.

2. Bowker W, Meredith HV. A metric analysis of the facial profile. Angle Orthod. 1959;29(3):146-6.

3. Brant JCO, Siqueira VCV. Alterações no perfil facial tegumentar avaliadas em jovens com Classe II, $1^{\text {a }}$ divisão, após o tratamento ortodôntico. Rev Dental Press Ortod Ortop Facial. 2006;11(2):93-102.

4. Chaconas SJ. A statistical evaluation of nasal growth. Am J Orthod. 1969:56(4):262-84.

5. Czarnecki ST, Nanda RS, Currier GF. Perceptions of a balanced facial profile. Am J Orthod Dentofacial Orthop. 1993;104(2):180-7.

6. Enlow DH, Harris DB. A study of the postnatal growth of the human mandible. Am J Orthod. 1964;50(1):25-50.

7. Fitzgerald JP, Nanda RM, Currier GF. An evaluation of the nasolabial angle and the relative inclinations of the nose and upper lip. Am J Orthod Dentofacial Orthop. 1992;102(4):328-34.

8. Formby WA, Nanda RS, Currier GF. Longitudinal changes in the adult facial profile. Am J Orthod Dentofacial Orthop. 1994;105(5):464-76.

9. Genecov JS, Sinclair PM, Dechow PC. Development of the nose and soft tissue profile. Angle Orthod. 1990;60(3):191-8.

10. Hoffelder LB, de Lima EM. Avaliação dos tecidos tegumentares da região do nariz, dos lábios e do mento em indivíduos brasileiros com Classe II esquelética. J Bras Ortodon Ortop Facial. 2006;11(61):70-82.

11. Hoffelder LB, de Lima EM, Martinelli FL, Bolognese AM. Softtissue changes during facial growth in skeletal Class II individuals. Am J Orthod Dentofacial Orthop. 2007;131(4):490-5.

12. Holdaway RA. The soft tissue covering of the skeletal face as related to orthodontic problems. Am J Orthod. 1964;50(6):405-20.

13. Koch R, Gonzales A, Witt E. Profile and soft tissue changes during and after orthodontic treatment. Eur J Orthod. 1979;1(3):193-9.

14. Lessa FCR, Enoki C, Feres MFN, Valera FCP. Lima WTA, Matsumoto MAN. Influência do padrão respiratório na morfologia craniofacial. Rev Bras Otorrinolaringol. 2005;71(2):156-60.

15. Maltagliati LA, Henriques JFC, Janson G. A influência do tratamento ortopédico nas estruturas faciais de indivíduos com má oclusão de Classe II, $1^{\text {a }}$ divisão: um estudo comparativo. J Appl Oral Sci. 2004;12(2):164-70.

16. Pereira PSG, Kajiwara JK, Grellet M. Estudo morfológico do desenvolvimento da cartilagem quadrangular do nariz e implicações nas cirurgias septoplásticas. Rev Bras Otorrinolaringol. 2002;68(2):209-17.
17. Posen JM. A longitudinal study of the growth of the nose. Am J Orthod. 1967;53(10):746-56.

18. Prahi-Andersen B, Ligthelm-Bakker AS, Wattel E, Nanda R. Adolescent growth changes in soft tissue profile. Am J Orthod Dentofacial Orthop. 1995;107(5):476-83.

19. Proffit WR, Fields HW, Sarver DM. Contemporary orthodontics. $4^{\text {th }}$ ed. St. Louis: C.V. Mosby; 2007.

20. Reis SAB, Capelozza Filho L, Cardoso MA, Scanavini MA. Características cefalométricas dos indivíduos Padrão I. Rev Dental Press Ortod Ortop Facial. 2005;10(1):67-78.

21. Ricketts RM. Planning treatment on the basis of the facial pattern and an estimate of its growth. Angle Orthod. 1957;27(1):14-37.

22. Ricketts RM. A influence of orthodontic treatment on facial growth and development. Angle Orthod. 1960;30(3):103-33.

23. Rosenstein SW. A longitudinal study of anteroposterior growth of the mandibular symphysis. Angle Orthod. 1964;34(3):155-67.

24. Wieler WJ, Barros AM, Barros LA, Camargo ES, Ignácio SA, Maruo $\mathrm{H}$, et al. A combined protocol to aid diagnosis of breathing model. J Dent Clin Res. 2007;3(2):101-14.

25. Saga AY. Estudo comparativo das dimensões craniofaciais entre respiradores predominantemente nasais e bucais na maloclusão Classe II, divisão 1 de Angle. 2002 [dissertação]. Curitiba (PR): Universidade Católica do Paraná; 2002.

26. Salgado JAP, Moraes LC, Castilho JCM, Moraes MEL. Avaliação do ângulo nasolabial, em radiografia cefalométricas laterais, dividido em ângulo superior e inferior, por uma linha paralela ao plano de Frankfort, em indivíduos portadores de má-oclusão Classe II e Classe III de Angle. Ciênc Odontol Bras. 2003;6(3):40-7.

27. Spinelli MLM, Casanova PC. Respiração bucal. 2002. [Acesso $12 \mathrm{fev}$ 2002]. Disponível em: www.odontologia.com.br/artigos.

28. Subtelny JD. A soft tissue growth and treatment changes. Am J Orthod. 1961;31(2):105-22.

29. Steiner CC. Cephalometrics for you and me. Am J Orthod. 1953;39(10):729-55.

Enviado em: 7 de novembro de 2007

Revisado e aceito: 25 de fevereiro de 2009

Endereço para correspondência

Orlando Tanaka

Rua Imaculada Conceição, 1155 - Centro

CEP: 80.215-901 - Curitiba / PR

E-mail: tanakaom@gmail.com 